\title{
Possibilities to Recycle Plastic Waste in Cementitious Materials
}

\author{
Marija Vaičiené $\dot{1}^{*}$, Jurgita Malaiškiené2 \\ ${ }^{I}$ Faculty of Civil Engineering, Vilnius College of Technologies and Design, Vilnius, Lithuania \\ ${ }^{2}$ Faculty of Civil Engineering, Vilnius Gediminas Technical University, Vilnius, Lithuania
}

Received 4 February 2020; accepted 31 March 2020

\begin{abstract}
In the paper, the changes of properties of expanded clay concrete when a part of the coarse aggregate is replaced with plastic waste are discussed upon. First of all, standard expanded clay concrete specimens were formed, and then 5\%,10\%, 20\% share of the fraction 4/8 of the expanded clay aggregate was replaced with plastic waste. The properties of expanded clay concrete, such as the density of the mixture, the slump, the density of the dried expanded clay concrete specimens, the ultrasonic pulse velocity, the water absorption, and the compressive strength, were established and analyzed; in addition, a microstructural examination was carried out. It was found that upon striving to use the maximum share of waste $(20 \%)$, it is possible to ensure about $4 \%$ higher density of expanded clay concrete and almost 50\% higher compressive strength, as compared to expanded clay concrete of the control specimens. SEM analysis showed that the same minerals, i.e. portlandite, ettringite, calcite and calcium hydro silicates were identified in specimens from all batches.
\end{abstract}

Keywords: plastic waste, expanded clay concrete, compressive strength, SEM analysis.

\section{Introduction}

In the EU, the potential for recycling plastic waste remains largely unexploited. Reuse and recycling of end-of-life plastics is very low, particularly in comparison with other materials such as paper, glass or metals. Around 25.8 million tons of plastic waste is generated in Europe every year. Less than $30 \%$ of such waste is collected for recycling. A significant share of the said leaves the EU to be treated in third countries, where different environmental standards may be applied (European Commission, 2017). As packaging is one of the main uses of plastics, all plastic packaging should be recyclable by 2030 (European Commission, 2018).

In course of implementation the provisions of documents related to formation of circular economy and ensuring the cleaner production conception, when it is strived for higher efficiency of production and minimization of risks for humans and the environment, a reasonable utilization of industrial waste turns into a task of high importance. In the run of implementation, the waste recycling and utilization programs, a part of natural materials should be replaced with waste in future. To spare natural resources, it is necessary to use cheaper raw materials, i.e. waste from various branches of industry to a larger extent. Recycling plastic waste to produce new materials such as concrete seems to be one of the best ways to dispose plastics waste, because of its economic and ecological reason. One of the opportunities is use of plastic waste as coarse and fine aggregate in production of lightweight concrete.

Typically, aggregates constitute $60-75 \%$ by volume and $79-85 \%$ by mass in Portland cement concrete. Aggregates are significantly cheaper than cement, and hence they help to reduce the cost of the concrete (Sivakugan et al., 2016). Lightweight aggregates are used to produce lower density concretes, which are advantageous in reducing the self-weight of structures and also distinguish themselves for better thermal insulation, as compared to normal weight concrete (Illston \& Domone, 2001).

Ali et al. (2018) studied the impact of utilizing polyethylene beads for a total or partial replacement of limestone coarse aggregates on some properties of lightweight concrete. The unit weight of the developed mixtures was in the range of $1366-1744 \mathrm{~kg} / \mathrm{m}^{3}$ while the compressive strength was in the range of $17-27 \mathrm{MPa}$. Other researchers (Nursyamsi \& Zebua, 2017) investigated the compressive strength of light concrete of PET plastic waste as coarse aggregate. The use of coarse aggregate of PET plastic waste can produce $1741-1801 \mathrm{~kg} / \mathrm{m}^{3}$ light concrete. The maximum compressive strength was 16.6 MPa. Saxena et al. (2018) used plastic bottles as aggregate (fine and coarse) in concrete at various replacement percentages, i.e., $5 \%, 10 \%, 15 \%$ and $20 \%$ by weight of concrete. The residual compressive strength of concrete containing PET waste was investigated for exposure to $300{ }^{\circ} \mathrm{C}$ and $600{ }^{\circ} \mathrm{C}$

*Corresponding author. E-mail: marija.vaiciene@vtdko.lt

Copyright (C) 2020 The Author(s). Published by VGTU Press

This is an Open Access article distributed under the terms of the Creative Commons Attribution License (http://creativecommons.org/licenses/by/4.0/), which permits unrestricted use, distribution, and reproduction in any medium, provided the original author and source are credited. 
elevated temperatures. The analysis of test results indicated lower compressive strength of concrete containing waste plastic PET aggregate. Results showed better resistance to impact loading in case of plastic concrete when compared to control concrete.

Recently, researchers (Islam et al., 2016) have tested the effects of waste PET as a coarse aggregate on the properties of fresh and hardened concrete. Research results show that increasing the W/C ratio increases the slump of mixture, reduces the compressive strength and the density of specimens. When W/C is 0.48 , the slump of mixture is obtained to be from $20 \mathrm{~mm}$ to $50 \mathrm{~mm}$, the compressive strength is in the range of (20-28) MPa and the density $(1950-2050) \mathrm{kg} / \mathrm{m}^{3}$. Saikia and Brito (2014) tested the effects of the size and the shape of recycled polyethylene terephthalate aggregate on the fresh and hardened properties, including abrasion resistance, of concrete. 5\%, 10\% and $15 \%$ in volume of natural aggregate in the concrete mixes were replaced by an equal volume of three differently shaped and sized PET-aggregates. The results indicate that the slump of fresh concrete increases slightly with the incorporation of pellet-shaped PET-aggregate. Flakier plastic aggregate sharply decreases the slump of the fresh concrete and it further decreases if the content and the size of this type of PET-aggregate increase. The compressive strength, tensile splitting strength, modulus of elasticity and flexural strength of concrete deterioration due to the incorporation of PET-aggregate and the deterioration of these properties intensifies with increasing the content of this aggregate.

Scientists (Nikbin et al., 2016) have shredded PET waste up to $7 \mathrm{~mm}$ and used it as a fine aggregate in concrete mixtures. Concrete specimens in 5\% sulphur solution have been maintained for 15, 30 and 60 days. Specimens with the highest content of PET waste are characterized by the lowest mass loss. In the work (Badache et al., 2018) have tested thermo-physical and mechanical characteristics of sand-based lightweight composite mortars with recycled high-density polyethylene (HDPE). The results have shown that increasing content of HDPE waste reduced the density of mixtures and hardened specimens; however, HDPE waste negatively affects mechanical properties of mortar specimens. On replacing sand with polyethylene waste, the compressive strength after 3, 7, 28, 90 and 180 days reduces, as compared to control specimens. The reduction in compressive strength is determined by low adhesion strength between HDPE plastic waste surface and the cement stone. Similar researches are conducted by other scientists (Akçaözoğlu et al., 2010), who had tested the shredded waste PET bottles as aggregate in lightweight concrete. Compressive strength results after 1, 3, 7, 28, 90 and 180 days show that after 28 days of hardening, the property reaches its value of (22.4-28.3) MPa. The density of dried specimens ranges from $1552 \mathrm{~kg} / \mathrm{m}^{3}$ to $1840 \mathrm{~kg} / \mathrm{m}^{3}$ and water absorption - from $11.9 \%$ to $14.8 \%$.

In the literature (Thorneycroft et al., 2018), showed: the replacing 10\% sand by volume with recycled plastic is a viable proposition that has the potential to save 820 million tonnes of sand in India every year.

Researchers (Coppola et al., 2016, 2018) were investigating the foamed plastic waste as natural aggregates replacement in lightweight mortar. Their results showed that plastic aggregates reduced both mortar density and thermal conductivity; water vapour permeability increased while capillary water absorption decreased, on the increasing the sand replacement, a reduction of mortar consistency was observed and, as expected, also mechanical properties decrease.

In the work (Aldahdooh et al., 2018) was investigated the potential of plastic waste aggregates as a partial aggregate replacement on properties of normal concrete, in which $30 \%$ of the total aggregate volume contains plastic waste aggregates. The results confirmed that response surface methodology prediction showed satisfactory results in optimizing the content of plastic waste aggregates in normal concrete production. Moreover, plastic waste aggregates can be used as aggregates for the production of normal concrete with acceptable engineering properties.

In the literature (Zaleska et al., 2018), there is a number of studies reporting that the designed lightweight concretes containing plastic waste aggregates present a prospective solution from the points of view of both plastic waste disposal and improvement of buildings' energy efficiency.

Several researchers (Shamsaei et al., 2017; Bansal et al., 2017) were investigating the effect of plastic waste on roller compacted concrete pavement and modified bituminous concrete. According to the test results, the use of PE waste for more than $5 \%$ of the coarse aggregate of the mix are recommended for low traffic pavements, rural roads and sidewalks. Laboratory testing results indicate that by using plastic waste, bituminous concrete of the required strength and density can be obtained and an environment friendly green pavement can be prepared with less material cost.

Other researchers (Hama \& Hilal, 2017; Yang et al., 2015) carried out an investigation on using plastic waste to improve some properties of self-compacting concrete and self-compacting lightweight concrete. The experimental results showed that the plastic waste of different sizes (fine plastic waste, coarse plastic waste, and mixed plastic waste) and contents $(0,2.5,5,7.5,10$, and $12.5 \%)$ can be used successfully as a fine aggregate in self-compacting concrete. The compressive strength, splitting tensile strength and flexural tensile strength of self-compacting lightweight concrete are increased with the replacement of plastic contents until the sand substitution level goes up to $15 \%$.

Literature review shows that reuse of plastic waste in concrete mixtures may have positive effect on the properties of concrete, and such concrete is an environmentally friendly building material. 
This work analyses the possibility to utilize plastic waste in expanded clay concrete. The main aim of this work is to investigate two types of plastic waste and evaluate their impact on the physical \& mechanical properties and the structure of expanded clay concrete.

\section{Materials and research methods}

For the formation of expanded clay concrete specimens, the following raw materials are used: cement, natural sand, expanded clay with different fractions, superplasticizer, plastic waste and water. The binding material is Portland cement CEM I $42.5 \mathrm{R}$ (particle density $3.1 \mathrm{~g} / \mathrm{cm}^{3}$, bulk density $1.1 \mathrm{~g} / \mathrm{cm}^{3}$ ). The mineral composition of cement: $\mathrm{C}_{3} \mathrm{~S}$, $\%$ 62.5; $\mathrm{C}_{2} \mathrm{~S}, \%$ 9.6; $\mathrm{C}_{3} \mathrm{~A}, \%$ 7.1; $\mathrm{C}_{4} \mathrm{AF}, \%$ 11.5. The chemical composition of cement: $\mathrm{SiO}_{2}, \% 20.8 ; \mathrm{Al}_{2} \mathrm{O}_{3}, \% 6.1$; $\mathrm{CaO}, \%$ 63.5; $\mathrm{Fe}_{2} \mathrm{O}_{3}, \% 3.4 ; \mathrm{K}_{2} \mathrm{O}, \% 1.0 ; \mathrm{Na}_{2} \mathrm{O}, \% 0.3 ; \mathrm{SO}_{3}, \% 0.8$.

The sand fraction 0/4 conforms to provisions of the standard LST EN 12620. Sand particles density is $2.5 \mathrm{~g} / \mathrm{cm}^{3}$, water absorption $-0.57 \%$, bulk density $-1.575 \mathrm{~g} / \mathrm{cm}^{3}$. The curve of granulometric composition of sand is provided in Figure 1.

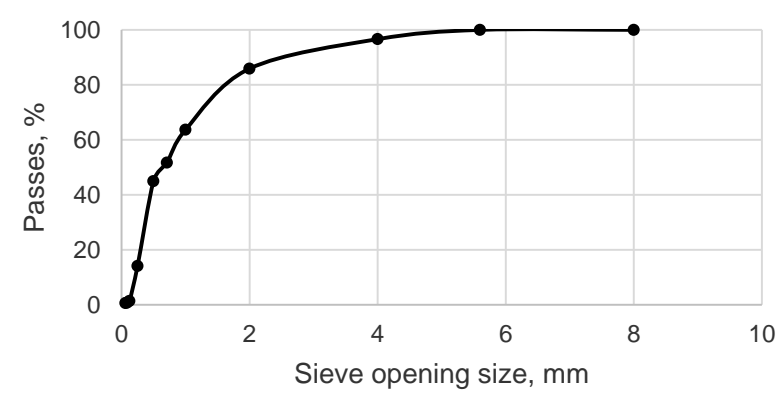

Figure 1. Granulometric composition of sand

Properties of expanded clay conform the requirements of standard LST EN 14063. Bulk density (4/8) $290 \mathrm{~kg} / \mathrm{m}^{3}$, bulk density (8/16) $250 \mathrm{~kg} / \mathrm{m}^{3}$, particle density (4/16) $410 \mathrm{~kg} / \mathrm{m}^{3}$, water absorption after $24 \mathrm{~h}(4 / 16) 17.5 \%$, compressive strength (4/8) $1.97 \mathrm{MPa}$, compressive strength (8/16) $1.11 \mathrm{MPa}$.

A superplasticizer based on polycarboxylates is used in all mixtures. It is of liquid state; its density is $1.07 \mathrm{~g} / \mathrm{cm}^{3}$. Superplasticizer conforms to the provisions of LST EN 934-2. Water is used according to the provisions of LST EN 1008.

Two types of waste are presented in Figure 2. A type waste (shredded HDPE - high density polyethylene) is produced of plastic packaging waste. Processing stages of this type waste include sorting, shredding (coarse and fine fractions), washing and drying. B type waste (LDPE - low density polyethylene) is produced of plastic covers' waste.

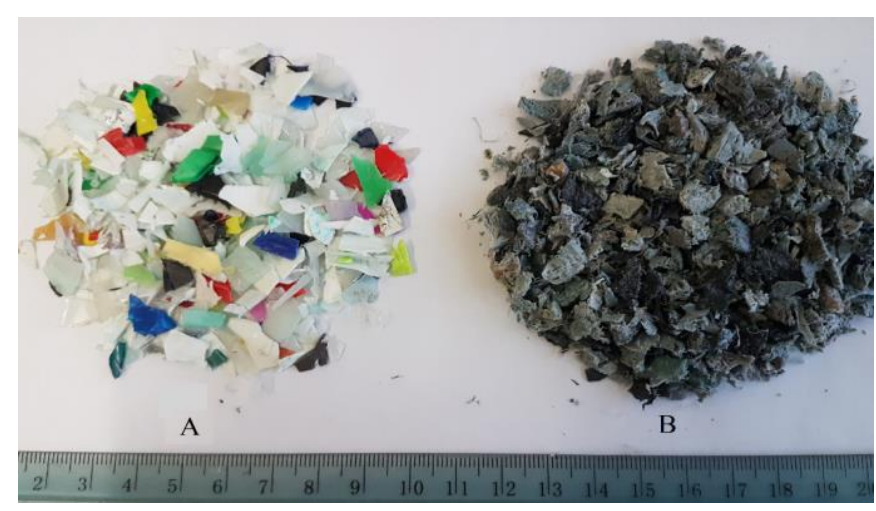

Figure 2. Image of tested waste

It can be seen from Figure 2 that the average size of waste is up to $1 \mathrm{~cm}$. A type waste has slimy and dense structure, B type waste is more porous and has rough surface. The bulk density of waste is $260 \mathrm{~kg} / \mathrm{m}^{3}$. The image of plastic waste microstructure is presented in Figure 3 (500x magnification). It can be seen from the photos that the surface of A type waste is even and the waste is of high density. Whereas the surface of B type waste is rougher, as compared to A type waste: small adhered particles (up to $2 \mu \mathrm{m}$ ) and pores are visible on it. 
In course of EDS analysis of plastic waste, the elementary composition of A type and B type waste was established. It is presented in Table 1 below. The elementary composition has been calculated in several points and areas and then the average value of the results was calculated. The elementary composition shows the waste to be polymers with small additive of calcium (the device does not fix hydrogen). The elementary composition of waste of both types is very mush alike; however, the contents of carbon and calcium were found higher and the content of oxygen in it was found some lower in B type waste, as compared to A type waste.

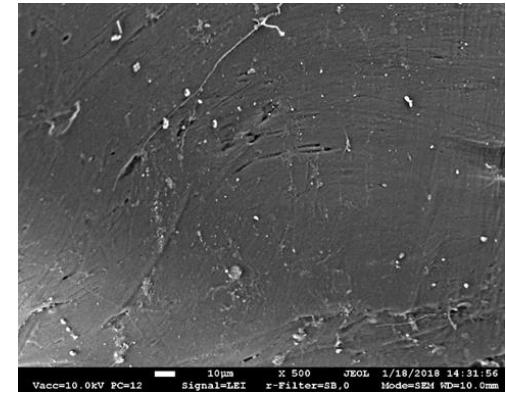

a)

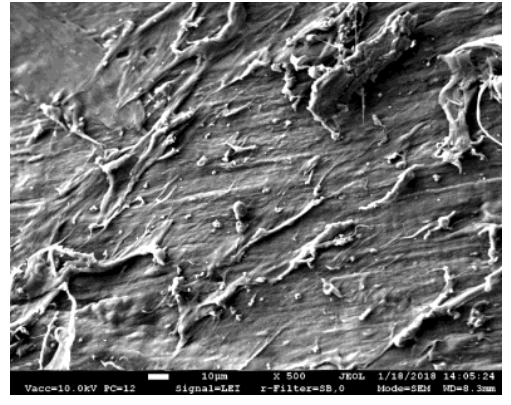

b)

Figure 3. The images of plastic waste microstructure: a) A type waste; b) B type waste

Table 1. The elementary composition of plastic waste

\begin{tabular}{|c|c|c|c|}
\hline Marking of waste & C, $\%$ & O, $\%$ & Ca, \% \\
\hline A & 87.4 & 11.9 & 0.7 \\
\hline B & 89.3 & 9.6 & 1.1 \\
\hline
\end{tabular}

Compositions and densities of expanded clay concrete mixtures, determined according to provisions of LST EN 12350-6, are presented in Table 2 below. Expanded clay has been already saturated with water before using it in mixture (expanded clay has been immersed for 24 hours). The content of absorbed water is deducted from the calculated content of water $\left(155 \mathrm{~kg} / \mathrm{m}^{3}\right)$. The $\mathrm{W} / \mathrm{C}$ ratio is 0.5 . The content of waste is calculated in percent $(0 \%, 5 \%$, $10 \%$ ) of the fraction $4 / 8$ of expanded clay mass.

It can be observed from the results presented in Table 2 that the density of concrete mixture with waste (that replaces a fine aggregate) in all cases slightly increases, as compared to the control specimens. The difference is not high because bulk densities of aggregates vary in a small range: bulk density of waste is $260 \mathrm{~kg} / \mathrm{m}^{3}$ and of the fraction $4 / 8$ of expanded clay $-290 \mathrm{~kg} / \mathrm{m}^{3}$. An increase in density is determined by the shape of aggregates. Waste is more flat and squeezed in cement matrix.

Table 2. Compositions of expanded clay concrete mixtures

\begin{tabular}{|c|c|c|c|c|c|c|c|c|c|}
\hline \multirow[b]{2}{*}{ Designation } & \multicolumn{8}{|c|}{ Composition of expanded clay concrete, $\mathrm{kg} / \mathrm{m}^{3}$} & \multirow[b]{2}{*}{$\begin{array}{c}\text { Mix } \\
\text { density, } \\
\mathrm{kg} / \mathrm{m}^{3}\end{array}$} \\
\hline & $\begin{array}{l}\text { Cement, } \\
\mathrm{kg} / \mathrm{m}^{3}\end{array}$ & $\begin{array}{l}\text { Sand, } \\
\mathrm{kg} / \mathrm{m}^{3}\end{array}$ & $\begin{array}{c}\text { Expanded } \\
\text { clay } 4 / 8, \\
\mathrm{~kg} / \mathrm{m}^{3}\end{array}$ & $\begin{array}{c}\text { Expanded } \\
\text { clay } 8 / 16, \\
\mathrm{~kg} / \mathrm{m}^{3}\end{array}$ & $\begin{array}{l}\text { Water, } \\
\mathrm{kg} / \mathrm{m}^{3}\end{array}$ & $\begin{array}{c}\text { Superplasticizer } \\
\mathrm{kg} / \mathrm{m}^{3}\end{array}$ & $\begin{array}{l}\text { Waste A, } \\
\mathrm{kg} / \mathrm{m}^{3}\end{array}$ & $\begin{array}{l}\text { Waste B, } \\
\mathrm{kg} / \mathrm{m}^{3}\end{array}$ & \\
\hline $\mathrm{K}$ & 310 & 680 & 142 & 142 & 127 & 3.1 & 0 & 0 & 1463 \\
\hline WA5 & 310 & 680 & 135 & 142 & 127 & 3.1 & 7 & 0 & 1516 \\
\hline WA10 & 310 & 680 & 128 & 142 & 127 & 3.1 & 14 & 0 & 1475 \\
\hline WB5 & 310 & 680 & 135 & 142 & 127 & 3.1 & 0 & 7 & 1433 \\
\hline WB10 & 310 & 680 & 128 & 142 & 127 & 3.1 & 0 & 14 & 1543 \\
\hline WAB10 & 310 & 680 & 110 & 142 & 127 & 3.1 & 14 & 14 & 1485 \\
\hline
\end{tabular}

$(100 \times 100 \times 100) \mathrm{mm}$ sized specimens have been formed of the prepared mixture and maintained for 1 day under normal conditions and then, for 27 days in water which temperature is $20^{\circ} \mathrm{C}$. The production and hardening of concrete specimens for the determination of strength was carried out in accordance with provisions of LST EN $12390-2$. Strength of concrete specimens is determined according to provisions of LST EN 12390-3. Density - based on the requirements of LST EN 12390-7. Water absorption - in accordance with the literature reference (Mačiulaitis, 1996).

Ultrasound propagation time is determined using the equipment "Pundit 7" (frequency of converters is $54 \mathrm{kHz}$ ) and ultrasonic pulse velocity is calculated upon applying the following equation $(\mathrm{V}, \mathrm{m} / \mathrm{s})$ : 


$$
V=\frac{l}{\tau}
$$

where: $l$ - length of the specimen, $\mathrm{m} ; \tau$ - signal propagation time, $\mathrm{s}$.

For the analysis of microstructure, scanning electron microscope JEOL JSM-7600F is used. Its resolution is $1.5 \mathrm{~nm}$, magnification ranges from 25 to 1'000'000 times; during the tests, voltage of $10.0 \mathrm{kV}$ is used. The surfaces of tested specimens are coated with gold. The thermal conductivity coefficient was calculated according to the Table A6 - Concrete units with expanded clay aggregate provided in the standard EN 1745.

\section{Tests results and analysis}

The determined expanded clay concrete slump is presented in Figure 4. It may be seen from Figure 4 that the slump of mixtures with A type waste is about 2.5 times higher as compared to the control specimens or the specimens with B type waste. It may be caused by a higher density of the structure of A type waste, so it is slippery and absorbs water more heavily. The surface of B type waste is uneven where some open pores may be found.

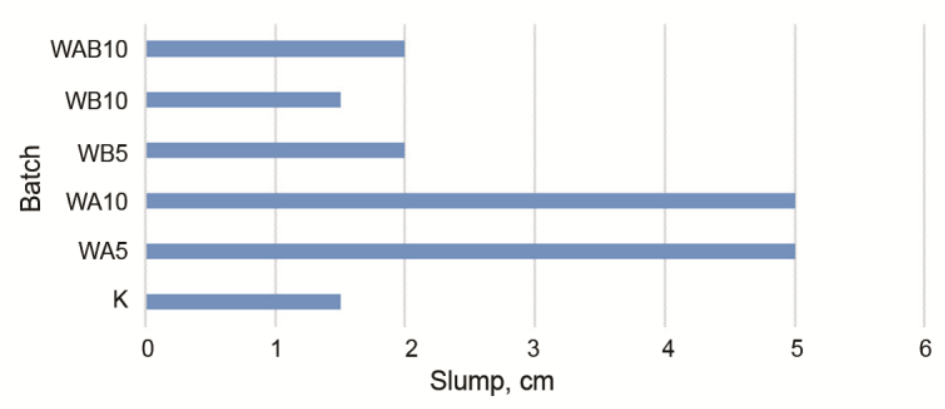

Figure 4. The dependence of expanded clay concrete slump on the content of waste

In Figure 5, the densities of dried specimens are presented. In all batches, the densities of expanded clay concrete are very much alike; the maximum difference amounts to about $5 \%$. The density of the control specimen was found to be the minimum, because the volume of the pellets of expanded clay is less as compared to plastic waste. In specimens with plastic waste, the amount of cement matrix is some higher.

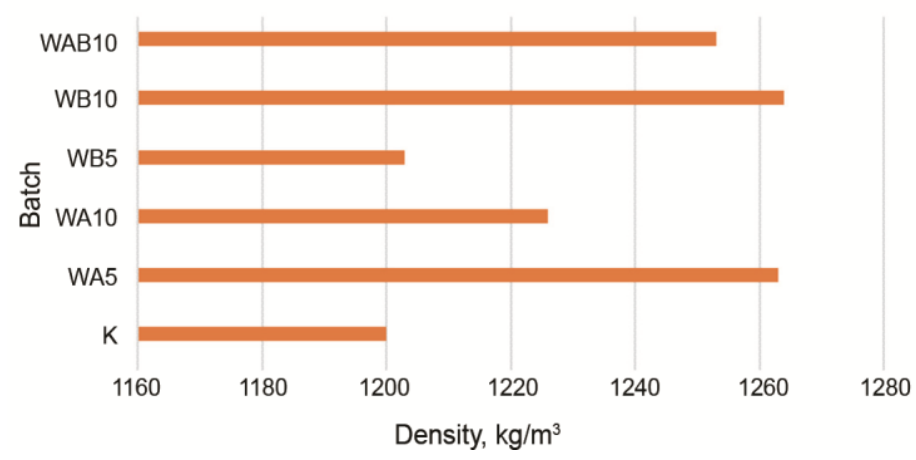

Figure 5. The dependence of expanded clay concrete density on the type of waste and its content

Then tests on ultrasonic pulse velocity in expanded clay concrete specimens were carried out. The results are provided in Figure 6. One of the lowest results of the ultrasonic pulse velocity was the velocity in control specimens. The ultrasonic pulse velocity in control specimens was lower by $8 \%$, as compared to specimens of the batch WA5. So, the density of specimens with A type waste is higher. The density of expanded clay concrete specimens with B type waste is lower. It might be explained by uneven surface of B type waste: when the cement matrix enters in contact with it, a larger number of open pores may be formed and a part of hard to reach small hollows is not filled.

The results of the tests on compressive strength of expanded clay concrete specimens are provided in Figure 7 below. The minimum compressive strength was found for control specimens without the waste. The maximum compressive strength was found for expanded clay concrete specimens with A type waste. When 5\% of expanded clay aggregate was replaced with A type waste, the compressive strength of expanded clay concrete increased by about $70 \%$, then the compressive strength began decreasing with increasing the content of the waste. A remarkable increase of the compressive strength (37\%) was also fixed in specimens with B type waste when its content was $10 \%$. Positive 
results were obtained when a mix of waste of both types (10\% of each) was used: in this case, the compressive strength of expanded clay concrete increased by about $50 \%$. The increase of the compressive strength was predetermined by the density of waste and the strength of waste itself that is fragile enough, as compared to expanded clay. In addition, a strong contact between waste and cement stone may be presumed to exist. To make sure of its existence, a microstructural analysis of expanded clay concrete specimens was carried out.

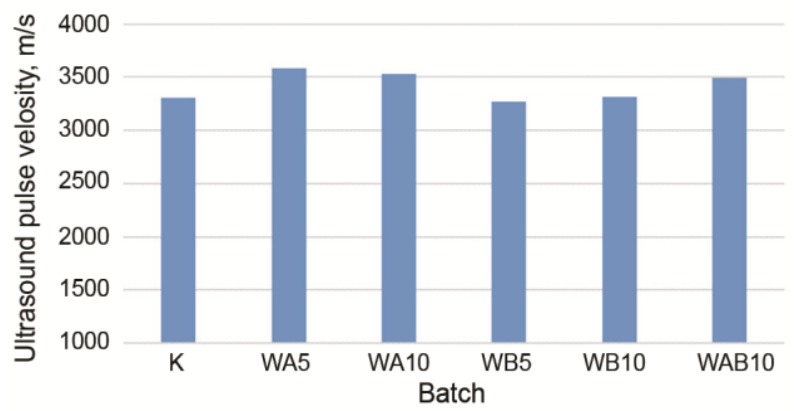

Figure 6. The dependence of expanded clay concrete ultrasonic pulse velocity on the type and the content of waste

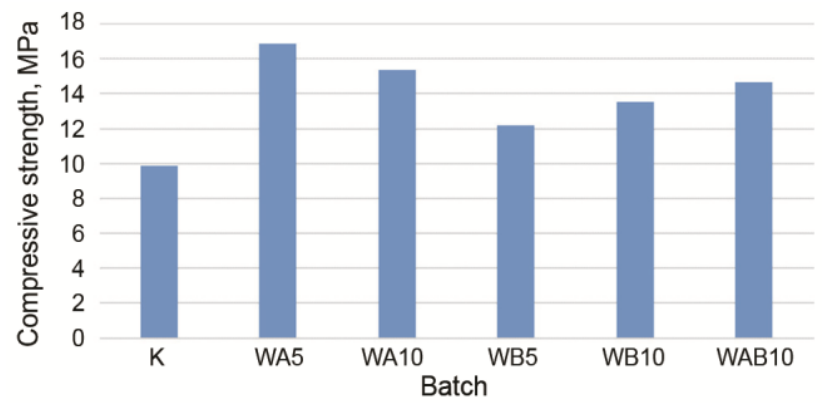

Figure 7. The dependence of expanded clay concrete compressive strength on the type and the content of waste

The analysis of the interaction zone between the cement stone and coarse aggregate is shown in Figure 8 . The Figure 8 shows how different aggregates, such as expanded clay as well as A and B type waste, grip with the cement matrix. It may be seen from the photos that cohesion is good in all the cases and no open cavities or cracks are visible in the interaction zone. However, it may be stated that cohesion in case of expanded clay concrete is stronger, because its pellets are porous and they as if coalesce with the cement stone, whereas in the case of plastic waste, a clear connecting line is visible between the plastic waste and the cement stone.

In Figure 9, the structure of expanded clay concrete (3000+ magnification) is presented. It may be seen that after 28 days of hardening, the structures of specimens differ considerably; however, practically analogous and standard cement stone minerals, such as portlandite, ettringite, calcite, and CSH, are indentified.

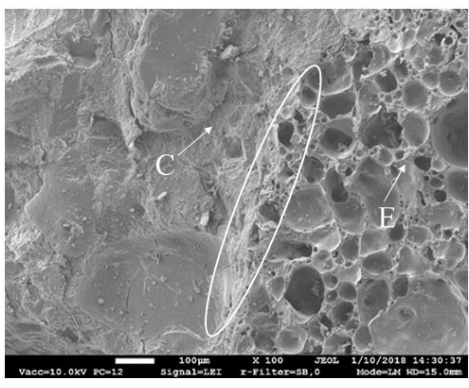

a)

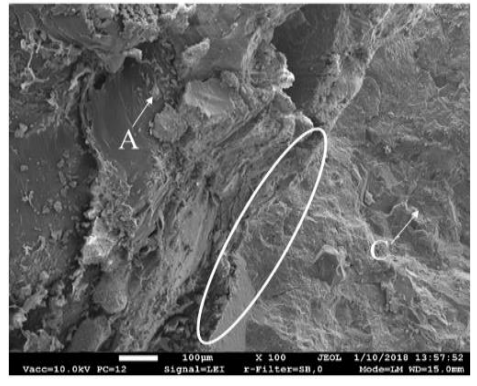

b)

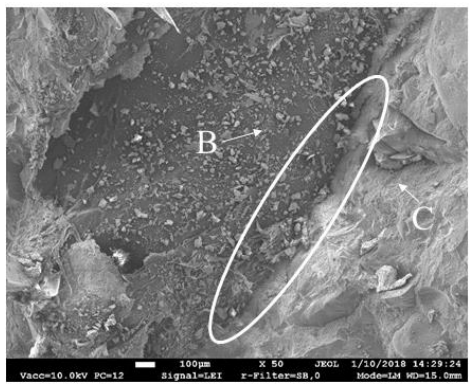

c)

Figure 8. Image of interaction zones between aggregates and cement stone. 1 - interaction zone between expanded clay (E) pellet and cement stone (C); 2 - interaction zone between A type waste (A) and cement stone (C); 3 - interaction zone between B type waste (B) and cement stone (C)

In the control specimens (Figure 9a), hexagonal lamellae of portlandite, needle-shaped aggregates of ettringite in pores and abundantly liquid phase glass fractions. That are atypical for specimens with waste may be seen when 
$5 \%$ of A type waste is added (Figure 9b), smaller portlandite crystals, bigger and more clearly expressed ettringite crystals as well as CSH areas that were hardly indentified in the structures are visible. When a higher amount of plastic waste (B type 10\%, Figure 9c) is added, ettringite is hardly identified; however, aggregates of portlandite are more abundant and its crystals are larger; in addition, some calcite and CSH are presented as well. In specimens where $20 \%$ of expanded clay was replaced with $10 \%$ A and B type plastic waste each, the ettringite crystals are not visible anymore, whereas portlandite and $\mathrm{CSH}$ predominate. The specimens with the waste distinguish are distinguished for a higher density of the structure; in addition, the number of open pores in it is less, so the compressive strength of the specimens with waste is higher. The results of SEM tests enable to state that plastic waste accelerates cement hydration process.

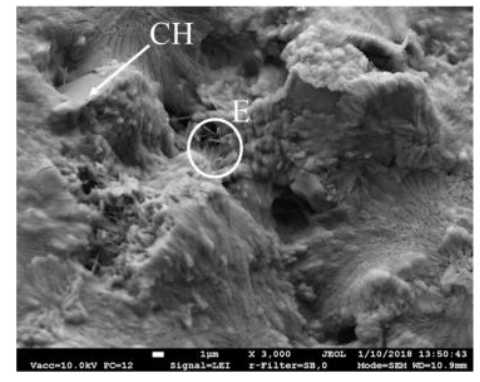

a)

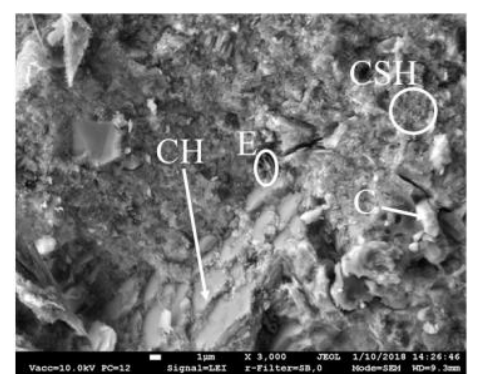

c)

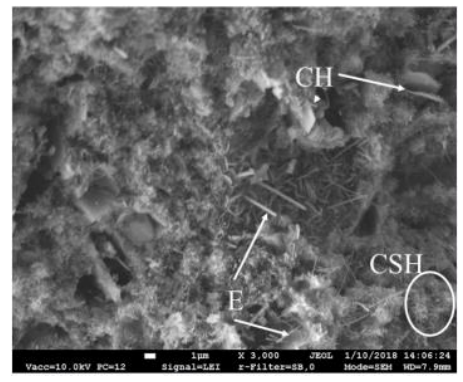

b)

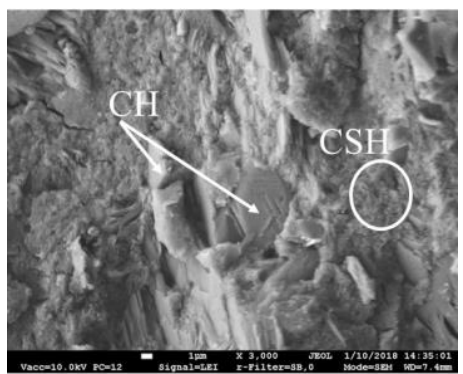

d)

Figure 9. Microstructure images of expanded clay concrete specimens: a) control specimen;

b) with 5\% of A type waste; c) with $10 \%$ of B type waste; d) $10 \%$ of A type and B type waste each

Water absorption results of expanded clay concrete are presented in Figure 10. After $72 \mathrm{~h}$ immersion in water, very similar values of water absorption were obtained. In the batches, water absorption varies between $9.97 \%$ and $10.6 \%$. The kinetics of water absorption differs slightly. In the expanded clay concrete specimens with A type waste, the rate of absorption process is the slowest and then they are distinguished for the lowest values of water absorption. Specimens with B type waste absorbed water more quickly. For batch WA5, the maximum values of density, ultrasonic pulse velocity and compressive strength were obtained; in addition, they were distinguished for one of the highest values of density of the microstructure, so it is logical that the said batch was distinguished for the minimum water absorption.

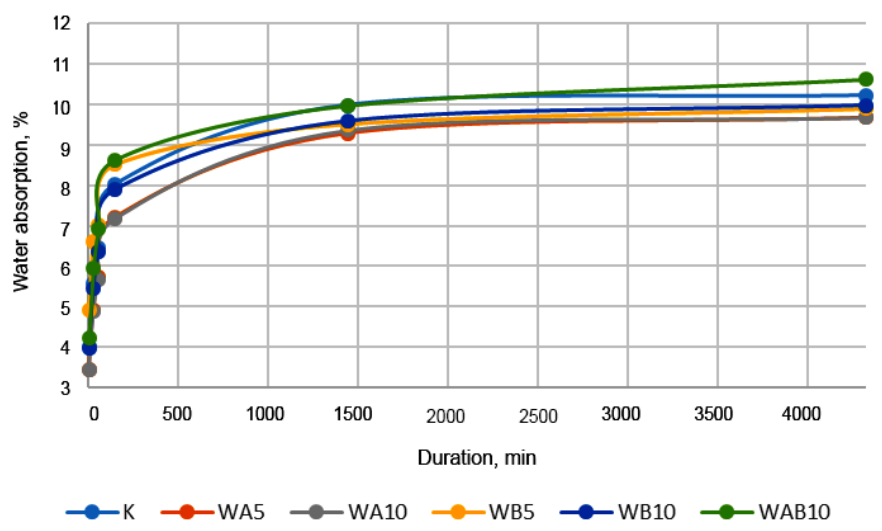

Figure 10. The dependence of water absorption on the type and the content of waste 
The results of calculation of thermal conductivity coefficient are provided in Figure 11. The minimum thermal conductivity coefficient with the average value of $0.41 \mathrm{~W} / \mathrm{mK}$ was found for the control specimens. The maximum thermal conductivity coefficient with the average value of $0.442 \mathrm{~W} / \mathrm{mK}$ was found for batches WA5 and WB10. Because the values of thermal conductivity coefficient changed about $8 \%$, it can be stated that the plastic waste predetermined the value of thermal conductivity coefficient of expanded clay concrete. In finer and more even plastic waste, smaller hollows and air gaps are formed, so higher density of the structure of concrete is ensured so heat exchange processes of lower intensity take place on its transportation by gas.

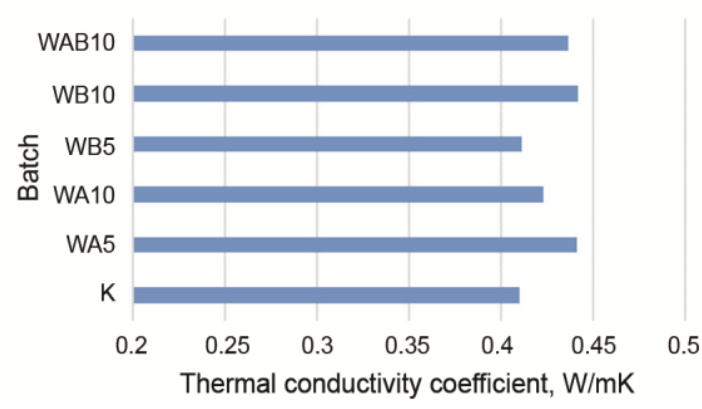

Figure 11. The dependence of expanded clay concrete thermal conductivity coefficient on the type and content of waste

\section{Conclusions}

In the paper, the effect of plastic waste of two types on the properties of expanded clay concrete has been analyzed. It was found that the said waste may be used in production of expanded clay concrete, because it provides a positive effect on physical \& mechanical properties and the structure of expanded clay concrete.

When $5 \%$ of expanded clay is replaced with A type plastic waste, the density of expanded clay concrete increases by $5 \%$, the ultrasound pulse rate increases by $8 \%$, the compressive strength increases by about $70 \%$, water absorption reduces by about $5 \%$, and the thermal conductivity coefficient increases by about $8 \%$, as compared to specimens without waste.

When $10 \%$ of expanded clay is replaced with B type plastic waste, the density of expanded clay concrete increases by $5 \%$, the ultrasonic pulse velocity remains similar, the compressive strength - increases by about $35 \%$, water absorption reduces by about $2 \%$, and the thermal conductivity coefficient increases by about $8 \%$, as compared to specimens without waste.

While assessing the values of thermal conductivity coefficient, the minimum change (equal to $0.4 \%$ ), as compared to the control specimens, was found for the specimens of batch WB5 where 5\% of fraction 4/8 of expanded clay was replaced with B type waste. The density of specimens of the said batch and the ultrasound pulse velocity remain analogous and the compressive strength increases up to $19 \%$.

SEM analyses shows that a rate of cement hydration in specimens with B type waste is higher and the main formed minerals include portlandite and CSH. In control specimens and the ones with 5\% A type waste, ettringite is identified in addition.

\section{References}

Akçaözoğlu, S., Atiş, C. D., \& Akçaözoğlu, K. (2010). An investigation on the use of shredded waste PET bottles as aggregate in lightweight concrete. Waste Management, 30, 285-290. https://doi.org/10.1016/j.wasman.2009.09.033

Aldahdooh, M. A. A., Jamrah, A., Alnuaimi, A., Martini, M. I., Ahmed, M. S. R., \& Ahmed, A. S. R. (2018). Influence of various plastics-waste aggregates on properties of normal concrete. Journal of Building Engineering, 17, 13-22. https://doi.org/10.1016/j.jobe.2018.01.014

Ali, M. R., Maslehuddin, M., Shameem, M., \& Barry, M. S. (2018). Thermal-resistant lightweight concrete with polyethylene beads as coarse aggregates. Construction and Building Materials, 164(10), 739-749. https://doi.org/10.1016/j.conbuildmat.2018.01.012

Badache, A., Benosman, A. S., Senhadji, Y., \& Mouli, M. (2018). Thermo-physical and mechanical characteristics of sand-based lightweight composite mortars with recycled high-density polyethylene (HDPE). Construction and Building Materials, 163(28), 40-52. https://doi.org/10.1016/j.conbuildmat.2017.12.069

Bansal, S., Misra, A. K., \& Bajpai, P. (2017). Evaluation of modified bituminous concrete mix developed using rubber and plastic waste materials. International Journal of Sustainable Built Environment, 6(2), 442-448. https://doi.org/10.1016/j.ijsbe.2017.07.009 
Coppola, B., Courard, L., Michel, F., Incarnato, L., \& Maio, L. (2016). Investigation on the use of foamed plastic waste as natural aggregates replacement in lightweight mortar. Composites Part B: Engineering, 99, 75-83. https://doi.org/10.1016/j.compositesb.2016.05.058

Coppola, B., Courard, L., Michel, F., Incarnato, L., Scarfato, P., \& Maio, L. (2018). Hygro-thermal and durability properties of a lightweight mortar made with foamed plastic waste aggregates. Construction and Building Materials, 170, $200-206$. https://doi.org/10.1016/j.conbuildmat.2018.03.083

European Commission. (2017). A European strategy for plastics in a circular economy. A strong and sustainable european plastics industry. https://ec.europa.eu/commission/sites/beta-political/files/plastics-factsheet-industry_en.pdf

European Commission. (2018). A European strategy for plastics in a circular economy. Communication from the commission to the European parliament, the council, the European economic and social committee and the committee of the regions. https://eur-lex.europa.eu/legal-content/EN/TXT/?uri=COM\%3A2018\%3A28\%3AFIN

Hama, S. M., \& Hilal, N. N. (2017). Fresh properties of self-compacting concrete with plastic waste as partial replacement of sand. International Journal of Sustainable Built Environment, 6(2), 299-308. https://doi.org/10.1016/j.ijsbe.2017.01.001

Illston, J. M., \& Domone, P. L. J. (2001). Construction materials: their nature and behaviour (3 ${ }^{\text {rd }}$ ed.). CRC Press. https://doi.org/10.4324/9780203478981

Islam, Md. J., Meherier, Md. S., \& Rakinul Islam, A. K. M. (2016). Effects of waste PET as coarse aggregate on the fresh and harden properties of concrete. Construction and Building Materials, 125(30), 946-951. https://doi.org/10.1016/j.conbuildmat.2016.08.128

Lietuvos Standartizacijos Departamentas. (2012a). LST EN 934-2:2009+A1:2012 Admixtures for concrete, mortar and grout Part 2: Concrete admixtures - Definitions, requirements, conformity, marking and labelling. https://eshop.lsd.lt/public\#/product/info/0a640324-60b6-1fee-8160-b65a184023a0

Lietuvos Stantartizacijos Departamentas. (2012b). LST EN 1745:2012 Masonry and masonry products - Methods for determining thermal properties. https://eshop.lsd.lt/public\#/product/info/0a640324-60b6-1fee-8160-b65861a87bf1

Lietuvos Standartizacijos Departamentas. (2003). LST EN 1008:2003 Mixing water for concrete - Specification for sampling, testing and assessing the suitability of water, including water recovered from processes in the concrete industry, as mixing water for concrete. https://eshop.lsd.lt/public\#/product/info/0a640324-60b6-1fee-8160-b654fa5f205d

Lietuvos Standartizacijos Departamentas. (2019a). LST EN 12350-6:2019 Testing fresh concrete - Part 6: Density. https://eshop.lsd.lt/public\#/product/info/0a640330-6d6f-1f57-816d-82bbae4e014b

Lietuvos Standartizacijos Deparatamentas. (2019b). LST EN 12390-2:2019 Testing hardened concrete - Part 2: Making and curing specimens for strength tests. https://eshop.lsd.lt/public\#/product/info/0a640330-6d6f-1f57-816d-82bbae4f014e

Lietuvos Standartizacijos Departamentas. (2019c). LST EN 12390-3:2019 Testing hardened concrete - Part 3: Compressive strength of test specimens. https://eshop.lsd.lt/public\#/product/info/0a640330-6d6f-1f57-816d-82bbae4d0149

Lietuvos Standartizacijos Departamentas. (2019d). LST EN 12390-7:2019 Testing hardened concrete - Part 7: Density of hardened concrete. https://eshop.lsd.lt/public\#/product/info/0a640330-6d6f-1f57-816d-82bbae4f014d

Mačiulaitis, R. (1996). Frost resistance and durability of façade bricks. Frostwiderstand und Dauerhaftigkeit keramischer Fassadenerzeugnisse. Fasadinès keramikos atsparumas šalčiui ir ilgaamžiškumas (132p.). Technika.

Nikbin, M. I., Rahimi, R. S., Allahyari, H., \& Fallah, F. (2016). Feasibility study of waste Poly Ethylene Terephthalate (PET) particles as aggregate replacement for acid erosion of sustainable structural normal and lightweight concrete. Journal of Cleaner Production, 126(10), 108-117. https://doi.org/10.1016/j.jclepro.2016.02.143

Nursyamsi, W., \& Zebua, S. B. (2017). The influence of PET plastic waste gradations as coarse aggregate towards compressive strength of light concrete. Procedia Engineering, 171, 614-619. https://doi.org/10.1016/j.proeng.2017.01.394

Saikia, N., \& Brito, J. (2014). Mechanical properties and abrasion behaviour of concrete containing shredded PET bottle waste as a partial substitution of natural aggregate. Construction and Building Materials, 52(15), 236-244. https://doi.org/10.1016/j.conbuildmat.2013.11.049

Saxena, R., Siddique, S., Gupta, T., Sharma, R. K., \& Chaudhary, S. (2018). Impact resistance and energy absorption capacity of concrete containing plastic waste. Construction and Building Materials, 176(10), 415-421. https://doi.org/10.1016/j.conbuildmat.2018.05.019

Shamsaei, M., Aghayan, I., \& Kazemi, K. A. (2017). Experimental investigation of using cross-linked polyethylene waste as aggregate in roller compacted concrete pavement. Journal of Cleaner Production, 165, 290-297. https://doi.org/10.1016/j.jclepro.2017.07.109

Sivakugan, N., Gnanendran, C. T., Tuladhar, R., \& Kannan, M. B. (2016). Civil engineering materials (1 ${ }^{\text {st }}$ ed.). Cengage Learning, Inc.

Thorneycroft, J., Orr, J., Savoikar, P., \& Ball, R. J. (2018). Performance of structural concrete with recycled plastic waste as a partial replacement for sand. Construction and Building Materials, 161, 63-69. https://doi.org/10.1016/j.conbuildmat.2017.11.127

Yang, S., Yue, X., Liu, X., \& Tong, Y. (2015). Properties of self-compacting lightweight concrete containing recycled plastic particles. Construction and Building Materials, 84, 444-453. https://doi.org/10.1016/j.conbuildmat.2015.03.038

Záleská, M., Pavlíková, M., Pokorný, J., Jankovský, O., Pavlík, Z., \& Černý, R. (2018). Structural, mechanical and hygrothermal properties of lightweight concrete based on the application of waste plastics. Construction and Building Materials, 180, 111. https://doi.org/10.1016/j.conbuildmat.2018.05.250 